\section{Original} Article

\begin{tabular}{|l|}
\hline Access this article online \\
\hline $\begin{array}{l}\text { Website: } \\
\text { www.ajobe.org }\end{array}$ \\
\hline \begin{tabular}{l} 
DOI: \\
10.4103/1817-7417.119956 \\
\hline Quick Response Code: \\
\hline
\end{tabular} \\
\end{tabular}

Address for correspondence: Dr. Willem Fourie, Department of Dogmatics and Christian Ethics, Faculty of Theology, University of Pretoria, Hatfield 0028, South Africa. E-mail: willem.fourie@up.ac.za

\title{
Can MNCs be held morally responsible for the unintended consequences of their operations?
}

\section{Willem Fourie}

Department of Dogmatics and Christian Ethics, Faculty of Theology, University of Pretoria, Hatfield 0028, South Africa

\section{ABSTRACT}

There seems to be popular consensus that multinational corporations (MNCs) should take responsibility for both the intended and unintended consequences of their operations. However, within the discipline of ethics, reflection on the responsibilities of MNCs continues to be highly controversial. In this article, we reflect on one of the more contentious issues in this debate, namely, the moral responsibility of MNCs for the unintended consequences of their operations. It is argued that at least two questions need to be addressed, namely, whether or not MNCs can be held morally responsible for anything and - should this be the case - what it actually means to hold the MNCs responsible.

Key words: Collective responsibility, multinational corporations, responsibility

\section{INTRODUCTION}

The controversy surrounding the responsibilities of multinational corporations (MNCs) - particularly in developing contexts- has all but subsided. A case in point is Walmart's recent acquisition of a majority share in the South African company Massmart.

The process, as it unfolded before South Africa's Competition Commission and Competition Tribunal, revealed a classic disagreement between business, organised labour and government (Garden, Balken and Van den Bergh, 2011; Competition Tribunal South Africa, 2011). Walmart and Massmart argued that the new configuration would effectively increase their profits and contribute positively to the living standards of South Africans by, amongst other things, providing access to more affordable products and employment opportunities. Organised labour argued that the merger would lead to a positive contribution to South African society only if very specific conditions were imposed.

After the conditional approval of the merger, three departments of the South African government issued a further statement on its possible effect (South African Press Agency, 2011; Lubin, 2011). The departments of trade and industry, agriculture and forestry, and economic development argued that the scale of Walmart's activities could be understood only by comparing it to the activities of a whole country, making government intervention necessary. Implicitly, the government departments activated the argument that the influence of MNCs stretches into the sphere of politics, but that MNCs do not have the corresponding structures to ensure accountability, which places an even greater responsibility on governments to impose conditions on mergers such as these.

The arguments above are by no means new or exclusively South African in nature. Discussions on topics as diverse as global warming, the responsibility of MNCs in the processes of democratisation and corporate social responsibility have in common that they deal with the intended and unintended consequences of the activities of MNCs. This topic is rapidly developing into a transdisciplinary field of study. Political scientist Mathias Koenig-Archibugi coined the term accountability gaps to designate the challenges that might result from governments assuming (or not assuming) new responsibilities in the light of the growing influence of MNCs (Koenig-Archibugi, 2004). Collusion between government officials and MNCs, for example, makes it possible for these enterprises to distort the outcome of 
political processes (Koenig-Archibugi, 2004:239). Even implicitly supporting authoritarian regimes can maintain repressive and unaccountable political structures by refraining from meaningful criticism. By leveraging their financial power, MNCs may also be in a position to initiate regulatory competition between different (developing) countries, in this way ensuring regulatory environments with deficient accountability structures (Koenig-Archibugi, 2004:241-242). In the same vein, Koenig-Archibugi argues that the institutional weaknesses of failing states can be used to mislead the respective societies by, for example, engaging in dangerous marketing practices (Koenig-Archibugi, 2004:244).

This article is meant as a contribution to the discussions on the responsibilities of MNCs. I will not, however, endeavour to address the theme as such. The argument is limited to investigating the responsibility of MNCs for the unintended consequences of their operations. It should also be noted that this article is meant as a conceptual contribution to the discussion. Ideally, the results of this article could form the basis for a more empirical article applying the conceptual findings. I find these interesting and potentially meaningful delimitations, as they might enable more focused reflection on case studies, such as the merger above, and on issues relating to global warming, or the debate on economic, political and environmental sustainability. Put in another way, this article addresses the following question: Can MNCs be held morally responsible for the unintended consequences of their operations?

The argument starts with the question of whether it makes conceptual sense to speak of the responsibilities of MNCs. With this question, we weigh in on the debate on collective responsibility. We proceed by asking what it means for MNCs to be held responsible for the consequences of their operations, should this be possible. In this section, we investigate the traditional and emerging traditions in understanding responsibility. Our consideration of these two questions will enable us to provide a tentative answer to the question of whether - and indeed how - MNCs can be held responsible for the unintended consequences of their operations.

\section{CAN MNCS BE HELD RESPONSIBLE FOR ANYTHING?}

When asking whether MNCs can be held responsible for the unintended consequences of their operations, one seems to assume that there might be a possibility for MNCs to be held responsible for at least the intended consequences of their operations. Such an assumption would be based on a further postulation, namely, that MNCs can act in a way that is different from the sum of the actions of the individuals who form part of the MNCs. Furthermore, the assumed agency is not of a merely technical nature but - in terms of our question, at least - seems to have a very definite moral dimension, creating the possibility for MNCs to be moral agents. It would seem, therefore, that before considering whether MNCs can be held responsible for the unintended consequences of their actions, we should first reflect on the possibility of MNCs being held morally responsible for anything. In reflecting on these questions, we find ourselves engaged in one of the most important debates in modern ethics, namely, the debate on collective responsibility.

The Second World War is possibly the single most important reason why ethical reflection on the possibility of a collective taking of responsibility for actions undertaken during the war has received so much attention in the $20^{\text {th }}$ century. In the aftermath of the war, some commentators argued that the German people as a whole should take responsibility for the atrocities committed, especially those towards Jews (cf. e.g. Viner, 1945; Janowitz, 1946; Roepke and Hayek, 1946). This line of argumentation understandably encountered strong reactions from various quarters. Some argued that it is impossible for a group to take responsibility for anything, as the moral agency of individuals may not be weakened so as to allow for the possibility of collective responsibility (cf. Lewis, 1948). Others argued that the German people should indeed accept responsibility for the Second World War, but not alone. Hannah Arendt argued, for example, that the system that made the war possible is by no means simply the fault of the Germans, but is, to a certain extent, the result of the human condition. She consequently argued that the whole of humanity should take responsibility for the Second World War (Arendt, 1945). In an existential manner, these discussions forced the importance and complexity of collective responsibility onto the academic agenda.

Changing political realities and configurations of power led to the gradual expansion of the debate to also include other types of collectives and to increase its conceptual precision. In his article "The corporation as a moral person," Peter French played a seminal role in both defending the concept of collective responsibility and including the corporation as a collective in the discussions (French, 1979). French argues that a corporation's internal decision structure (CID structure) proves that it fulfils the requirements for moral agency, which he regards as proof that collective responsibility is not only reasonable but also necessary (French, 1979:211). Such a structure - which consists of, at least, an "organizational or responsibility flow chart" and "corporate decision-making rules" (French, 1979:212) - "accomplishes a subordination and synthesis of the intentions and acts of various biological persons into a corporate decision" (French, 1979:212). This results in a CID structure licensing "redescriptions of events as corporate intentionality, while it does not obscure the private acts of executives, directors" (French, 1979:214). 
French's emphasis on the significance of the features of a group has become one of at least three core arguments in defence of collective responsibility (May, 1991:3). A second argument holds that the common interests or needs of a group, that is, their group solidarity (Feinberg, 1988) or group consciousness or "we-intentions" (Tuomela and Miller, 1988), merit ascribing responsibility to the collective. A third argument holds that the benefits individuals receive as a result of their group membership, such as social status, recognition and even access to opportunities, morally requires of members the willingness to take responsibility for the associated costs of actions done on behalf of, or in the interest of, the group (McGary, 1986; Thomson, 2006).

The proponents of collective responsibility - also in its more subtle reformulations - face strong opposition. Lewis's early article, titled "Collective responsibility" and published in 1948, had already vigorously argued against collective responsibility (Lewis, 1948). He contended that respect for the dignity of an individual means acknowledging that only individuals can bear responsibility. He held the view, along with many others (cf. Downie, 1969), that collectives can, at most, be regarded as having aggregated individual responsibility, and by no means conglomerated individual responsibility, as proposed by French (cf. Corlett, 2001 for a more recent and more nuanced defence of collective responsibility). This is especially the case when one views collective responsibility as a moral category and not only in terms of the irreducibility and non-irreducibility of judgements. ${ }^{1}$

In terms of our argument, it is important to note Manuel Velasquez's influential response to Peter French's proposal outlined above (Velasquez, 1983). His initial response centred on French's inability to prove that actions can be derived from a corporation's intentions (mens rea) and be attributed to the corporation (actus rea) (Velasquez, 1983:3-4). Velasquez essentially argues that actions cannot originate in the corporation, but that they always originate in the members of the corporation. It is impossible to prove, according to Velasquez, that corporations act, as it is always their members who perform the respective acts (Velasquez, 1983:6). He also disputes French's claim that the CID structure of corporations is sufficient proof that corporations can have intentions. In a similar vein, he argues that the corporation only carries out the intentions of its constitutive members - even though it cannot be disputed that the corporation influences these very same intentions (Velasquez, 1983:8).

In a more recent article on the same topic, Velasquez continues to argue against the possibility of the collective responsibility of corporations (Velasquez, 2003). He devotes much of his attention to the mens rea, or intentions, of corporations. According to Velasquez, intention can be attributed to corporations in at least two ways, namely, as intrinsic intention and as as-if intention (Velasquez, 2003:546). He argues that corporations do not intend in an intrinsic - literal - sense, but much rather in an as-if sense. He describes the distinction by using the market as example:

The collection of people that constitute a market, for example, does not have a literal group mind in which conscious beliefs, intentions, and purposes inhere, and so it cannot have intrinsic intentionality. When we describe a collection of people as having certain beliefs and intentions, we must be attributing as-if intentionality to the collection, and not intrinsic or literal intentionality. On the other hand, the individual people who make up the group have intrinsic intentionality because each of them has a conscious mind in which literal beliefs, intentions, and purposes can reside (Velasquez, 2003:547).

He refines this distinction further by also distinguishing between two kinds of as-if intentionality, namely, descriptive and prescriptive as-if intentionality (Velasquez, 2003:547). The descriptive sense describes intentionality "by analogy to human intentionality," and the prescriptive sense means that "a person or group of persons asserts, declares, or authorizes that some object or group is to be dealt with as if it had a certain kind of (intrinsic) intentionality" (Velasquez, 2003:547-548). The latter sense is common in the legal system. In terms of Velasquez's argument, it would be possible, then, for an action with negative consequences to occur as a consequence of the facilitation of an organisation, without any human person being morally responsible for these consequences (Velasquez, 2003:550). He terms such occurrences accidents, and argues that the corporation can be held financially responsible without implying any form of moral responsibility (Velasquez, 2003:550).

The discussion of the different viewpoints above may clarify a number of concepts. It is important to note that the related issues of intention and agency play a central role in arguing either for or against the collective responsibility of corporations. The ongoing discussion between French and Velasquez exemplifies what is perceived as the decisive importance of intention in proving the possibility of collective responsibility.

However, it may be that the importance of intention in the debates outlined above may reveal as much about the debate as it exposes about the understanding of responsibility that forms the basis of the debate. The next section argues that it is mostly a retrospective understanding of responsibility that is used in these debates. It is suggested that a prospective understanding of responsibility can open new avenues for considering the collective responsibility of collectives, as well as their moral responsibility for the unintended consequences of their operations. 
WHAT DOES IT MEAN FOR MNCS TO BE HELD RESPONSIBLE FOR SOMETHING?

Ascertaining whether or not corporations can be held responsible for the unintended consequences of their operations requires reflection on at least two fundamental matters. In the previous section, we reflected on the possibility of corporations taking collective responsibility for their actions. The review of the debates on collective responsibility highlighted two features. The first is that there is clearly no consensus on the possibility of collective responsibility. The second is that it seems as if a very specific understanding of responsibility underlies these debates. This feature coincides with the second fundamental matter that requires reflection when considering the moral responsibility of corporations, namely, what we actually mean by the concept of responsibility. In this section, I contend that a more complex reflection on the concept of responsibility could provide a point of focus in the quagmire sketched in the previous section.

At least two traditions in understanding responsibility can be identified (De Villiers, 2002). Responsibility as imputation - or retrospective responsibility - continues to be the most prominent tradition (De Villiers, 2002:16). Etienne de Villiers summarises this understanding of responsibility as follows:

A person is ... morally guilty if it can be established that a negative outcome is causally linked to the actions and intentions of that person, and that his or her actions and intentions contradict the moral values of the particular society (De Villiers, 2002:17).

The focus on agency, intention and imputation gives this tradition a decidedly backward-looking character and conceptual proximity to legal processes. This character is clear when one considers Velasquez's definition of responsibility. Even though he acknowledges that three definitions of responsibility might exist, he nonetheless chooses to limit his reflection on collective responsibility to a very specific definition of responsibility:

The notion of responsibility that I want to discuss is a ...causal sense of responsibility. In this causal sense responsibility looks toward the past, toward some act or event that someone or something has already caused. The responsible party in this sense is the party (or parties) that is identified as the (or one of the) primary, or most salient, or most significant, cause of the past act or event (Velasquez, 2003:532).

French similarly remains within the retrospective tradition when he develops his understanding of responsibility as either pinning blame on somebody or "having a liability to answer" (French, 1973:210).

The second tradition - in a sense an emerging tradition - can be termed prospective responsibility. Whereas retrospective responsibility looks back in order to identify moral agents with irresponsible intentions, prospective responsibility is forward-looking in nature (De Villiers, 2002:17). Arguably, the most prominent contemporary proponent of prospective responsibility is Hans Jonas. He bases his influential work on responsibility (Jonas, 1979) on the assumption that the expansion of human influence has fundamentally changed ethical premises (Jonas, 1984:1). According to Jonas, it is no longer true that the human condition is unchanging and readily understandable; it is no longer true that moral good is readily determinable; it is no longer true that human action and responsibility can be "narrowly circumscribed" (Jonas, 1984:1).

This led Jonas to a reformulation of Immanuel Kant's categorical imperative. Jonas attempted to subvert the certainty with which Kant assumed the possibility of a universal law, and its rational accessibility, in the light of a radical change in human nature and human influence. Jonas formulated the following categorical imperative: "Act so that the effects of your action are compatible with the permanence of genuine human life," and a lesser-known formulation: "Do not compromise the conditions for an indefinite continuation of humanity on earth" (Jonas, 1984:11). In order to reach this aim, Jonas proposes that his "ethics of the future" (Jonas, 1984:25) should be guided by the "heuristics of fear" (Jonas, 1984:26). According to Jonas, this is necessary, as "the perception of the malum is infinitely easier to us than the perception of the bonum," as it is "more direct, more compelling, less given to differences of opinion or taste, and, most of all, obtruding itself without our looking for it" (Jonas, 1984:27).

From the discussion above, it should be clear that Jonas emphasises the need for a forward-looking understanding of responsibility. A further feature is of even greater importance for the argument of this article: Jonas and other proponents of prospective responsibility loosen the connection between responsibility and intention. Intention does not become irrelevant, but the overriding concern is to develop the implications of a strong connection between responsibility and influence. In this scheme, reflection on the potential effects of certain actions is more important than isolating intentions. A prospective understanding of responsibility consequently creates the opportunity for proactive and collective processes of gaining consensus on shared challenges and the minimum requirements for averting catastrophe. It also provides potentially meaningful perspectives for our reflection on the possibility of MNCs taking responsibility for the unintended consequences of their operations.

Three points of connection in, and possibly even corrections to, the debate on collective responsibility can be identified. The first is the role that the context of unprecedented challenges and changes in the global and local flows of 
power plays in the theory of prospective responsibility. This implies a decidedly contextual understanding of responsibility. In this sense, it might provide conceptual texture to our reflection on the responsibilities of MNCs. The second point is subtler, but might contribute greatly to changing the mode of the discussion. A consideration of prospective responsibility is not so much concerned with proving beyond all doubt who was responsible for which actions, or how responsibility should be distributed. It starts with the fact of individual and collective influence, and provides a platform for dialogue on the best ways to use influence to ensure a sustainable future. It would seem that proving that MNCs facilitate far greater influence than the aggregate of the individuals who constitute the corporation is easier - and, some would argue, more meaningful - than proving the agency of MNCs. Thirdly, the theory on prospective responsibility widens the conceptual distance between the legal and moral spheres. It creates the opportunity for moral and legal transgressions not to be equated with one another, in contrast to most uses of responsibility in the traditional debates on collective responsibility.

Before we continue, we should add a disclaimer to the discussion thus far. The suggestion to incorporate prospective responsibility into the discussion on collective responsibility and, eventually, the moral responsibility of MNCs for the unintended consequences of their actions is not meant to imply that this emerging tradition should function on its own. On the contrary, a scheme that manages to include both retrospective and prospective dimensions of responsibility is viewed as the ideal. However, in this paper, the aim is more limited than to provide such a scheme: It is argued that the prospective dimension of responsibility provides an avenue for reflection on the moral responsibility of MNCs for the unintended consequences of their operations. In the following section, we will conclude our argument by applying our discussion to this theme.

\section{CAN MNCS BE HELD MORALLY RESPONSIBLE FOR THE UNINTENDED CONSEQUENCES OR THEIR OPERATIONS?}

The article started with the contention that significant societal actors across the globe view the influence of MNCs as greater than ever. It is possible to argue that MNCs are no longer analogous only to the citizens of their respective territories (Crane, Matten and Moon, 2008:17-49), but that they increasingly also function analogously to governments (Crane, Matten and Moon, 2008:50-89). This phenomenon is, at times, described as the "crisis of the welfare state" (cf. Garriga and Melé, 2004:56). Worldwide, democratically elected governments are experiencing difficulty in providing for the basic human needs of all their citizens. This is especially the case in countries with consolidated democratic institutions and developing economies, many of which are situated in sub-Saharan Africa. The regulation and control of economic activities are consequently becoming increasingly complex. New economic spaces are being created outside the borders of national states (Crane, Matten and Moon, 2008:457). MNCs are becoming relatively more mobile, and their ability to relocate to countries on the grounds of their favourable regulatory environments adds to the pressure on national governments. Governments are consequently "reluctant to impose extra regulation on business for fear of losing employment and tax income" (Crane, Matten and Moon, 2008:23).

At the same time, the nature and role of the business corporation is still evolving. A substantial increase in financial resources and political leverage has put corporations in completely new positions of influence with regard to political institutions. Business is no longer solely dependent on decisions made by democratically elected political leaders and their bureaucracies. This does not mean that the political sphere is now devoid of any influence, or at the mercy of business. The subprime mortgage and sovereign debt crises, and the enactment of the Sarbanes-Oxley Act in 2002 in the United States of America, illustrated the enduring influence and necessity of legitimate and strong political institutions. It should be added, however, that the relative power of political institutions is significantly lower in developing economies than in developed economies. Business enterprises - in particular, those operative in many different countries - have the power to make decisions, even when these are understood as purely financial, practical or organisational, and influence not only employees, customers and shareholders but also the general public of a certain territory. Advances and applications in information technology and biological sciences add to the influence of the business sector.

In a very real sense, these changes have necessitated renewed reflection on the moral responsibility of MNCs, as it would seem that the experienced realities of people across the globe are at odds with the ethical theory of collective responsibility. In the previous sections, we argued that the discussions on collective responsibility are limited to reflection on the retrospective dimension of responsibility. It was argued that incorporating the prospective dimension of responsibility would assist our reflection on the moral responsibilities of MNCs. This is done by placing the theory of responsibility within the context of current challenges and changes, loosening the connection between responsibility and intention, emphasising the connection between responsibility and influence, and emphasising the distinction between legality and morality.

These three conclusions seem to enable an affirmative yet qualified answer to the question of whether or not MNCs can be held morally responsible for the unintended consequences of their operations. The prospective dimension 
of responsibility and, therefore, the close connection between influence and responsibility opens the possibility of MNCs taking responsibility for the unintended consequences of their operations. It is a logical necessity that the influence of either an individual or a collective will have both intended and unintended consequences. Unfortunately, this does not imply that it would be possible to predict what the unintended consequences may be - using the past experience of MNCs and analogous organisations might be the best starting point for the ensuing dialogue. The prospective dimension of responsibility further rests on the acknowledgement that MNCs facilitate much greater influence than would have been possible if the activities of the individuals who constitute the MNCs were simply aggregated. In this regard, the development of new technologies and products, the engagements with state actors in, for example, legislative processes, the concentration of business activities in specific territories, legally required contributions over and above the taxes of employees, and many other examples can be presented. However, in this sense, "taking responsibility" does not seem to be equated with being liable for potential damages. Rather, it creates a platform for dialogue and proactive collective actions.

\section{FOOTNOTE}

${ }^{1}$ The debate between Cooper, 1968 and Downie, 1969 is one of the most prominent examples of this line of argumentation.

\section{REFERENCES}

Arendt, H. (1945). Organised guilt and universal responsibility. Jewish Frontier, 12, 19-23.

Competition Tribunal South Africa. (2011). Tribunal statement on the conditional approval of the merger between Wal-mart Stores Inc. and Massmart Holdings Limited - 31 May 2011. [Online] Available from: http://www.comptrib.co.za/publications/press-releases/wal-mart-andmassmart-31-may-2011/[Last accessed on 02 April 2012].

Cooper, D.E. (1969). Collective responsibility. Royal Institute of Philosophy, 43, 258-68.

C.J. Angelo. (2001). Collective moral responsibility. Journal of Social Philosophy, 32, 573-84.

Crane, A., Matten, D., and Moon, J. (2008). Corporations and citizenship (pp. 17-49) Cambridge: Cambridge University Press.

De Villiers, E. (2002). Who will bear moral responsibility? Communication, $28,16-21$.
Downie, R.S. (1969). Collective responsibility. The Journal of the Royal Institute of Philosophy, 44, 66-9.

French, P. (1979). The corporation as a moral person. American Philosophical Quarterly, 16, 207-15.

Feinberg, J. (1970). Doing and Deserving. Princeton, NJ: Princeton University Press.

Garden, M., Balken, J., and Van den Bergh, K. (2011). Massmart/ Walmart merger. [Online]. Available from: http://www.ens.co.za/ news/news_article.asp?ilD $=254$ andiType $=4$ [Last accessed on 02 April 2012].

Garriga, E. and Melé, D. (2004). Corporate social responsibility theories: Mapping the territory. Journal of Business Ethics, 53, 51-71.

Janowitz, M. (1946). German reactions to Nazi atrocities. American Journal of Sociology, 52, 141-6.

Jonas, H. (1979). Das Prinzip Verantwortung. Versuch einer Ethik für die technologische Zivilisation. Frankfurt a.M.: Suhrkamp.

Jonas, H. TransI. H. Jonas and D. Herr. (1984). The imperative of responsibility: In search of an ethics for the technological age. Chicago, IL: University of Chicago Press.

Koenig-Archibugi, M. (2004). Transnational corporations and public accountability. Government and Opposition, 39, 234-59.

Lewis, H.D. (1948). Collective responsibility. Philosophy, 23, 3-18.

Lubin, G. (2011). South Africa tells exactly why it is terrified of a WalmartMassmart merger. [Online]. Available from: http://articles.businessinsider. com/2011-08-03/news/30049056_1_wal-mart-walmart-walmex [Last accessed on 02 April 2012].

May, L. and Hoffman, S. (Eds.). (1991). Collective responsibility. Five decades of debate in theoretical and applied ethics. Lanham, MD: Rowman and Littlefield.

McGary, H. (1986). Morality and collective liability. Journal of Value Inquiry, 20, 157-65.

Roepke, W. and Hayek, F.A. (1946). The German dust-bowl. The Review of Politics, 8, 511-27.

South African Press Agency.(2011). Walmart-Massmart merger poses risk to SA: Ministers.[Online]. Available from: http://www.timeslive. co. za/ politics/2011/08/02/walmart-massmart-merger-poses-risk-to-sa-ministers [Last accessed on 02 April 2012].

Thomson, J. (2006). Collective responsibility for historic injustice. Midwest Studies in Philosophy, 30, 154-167.

Tuomela, R. and Miller, K. (1988). We-intentions. Philosophical Studies, $53,367-89$.

Velasquez, M. (1983). Why corporations are not morally responsible for anything they do. Business and Professional Ethics Journal, 2, 1-18.

Velasquez, M. (2003). Debunking corporate moral responsibility. Business Ethics Quarterly, 13, 531-62.

Viner, J. (1945). The treatment of Germany. Foreign Affairs, 23, 567-81.

How to cite this article: Fourie W. Can MNCs be held morally responsible for the unintended consequences of their operations? Afr J Bus Ethics 2013;7:26-31.

Source of Support: Nil, Conflict of Interest: None declared

\section{AUTHOR}

Willem Fourie teaches ethics at the University of Pretoria. His recent publications include the monograph Communicative freedom: Wolfgang Huber's theological proposal. 
Reproduced with permission of the copyright owner. Further reproduction prohibited without permission. 